\title{
Elementos para una crítica general de la propiedad: el trabajo inmaterial y la construcción económica de la escasez
}

\author{
Ariel Fazio ${ }^{1}$
}

Recibido: 12 de noviembre de 2018 / Aceptado: 8 de junio de 2019

Resumen. Teniendo como punto de partida la contraposición entre dos principales definiciones de lo económico, una formal y otra material o sustantiva, y en un contexto de nuevos cercamientos sobre la naturaleza y la cultura, se retoman las conceptualizaciones tradicionales de la propiedad privada para confrontarlas con la tendencia contemporánea hacia una creación artificial de escasez en la producción inmaterial. Desde aquí, se propone discutir las nociones tradicionales sobre la propiedad privada y su relación con la definición de lo económico, con el objetivo de proveer elementos conceptuales que puedan contribuir a un análisis crítico de la propiedad en tanto que institución social.

Palabras clave: economía; abundancia; propiedad intelectual; Robbins; Polanyi.

\section{[en] Elements for a general critique of property: immaterial labor and the economic construction of scarcity}

\begin{abstract}
Taking as its starting point the contrast between the two main definitions of economy, from the formal tradition and from the material or substantive tradition, and in a context of new enclosures on nature and culture, traditional conceptualizations of private property are taken back to confront them with the contemporary tendency towards an artificial creation of scarcity for the immaterial production. From here, we propose to discuss the traditional notions about private property and its relation to the definition of economy, with the ultimate objective of providing some conceptual elements that would contribute to a critical analysis of property as a social institution.
\end{abstract}

Keywords: economy; abundance; intellectual property; Robbins; Polanyi.

Sumario: 1. Introducción; 2. Los fundamentos de la propiedad privada; 3. Los nuevos cercamientos sobre el trabajo inmaterial; 4. La construcción económica de la escasez; 5. Consideraciones finales: repensar la propiedad, pensar el capitalismo; 6 . Referencias bibliográficas.

Cómo citar: Fazio, A. (2020): "Elementos para una crítica general de la propiedad: el trabajo inmaterial y la construcción económica de la escasez”, en Revista de Filosofía 45 (1), 161-177.

\footnotetext{
1 Departamento de Filosofía

Universidad de Buenos Aires

arielfazio@filo.uba.ar
} 


\section{Introducción}

La definición ortodoxa de economía ${ }^{2}$ se encuentra estrechamente vinculada a la institución de la propiedad privada como medio para una acumulación de carácter ilimitado, en contraposición con definiciones heterodoxas - pero también clásicas- ${ }^{3}$ que entienden lo económico como un medio para lograr las condiciones materiales de una «vida plena». Esta tensión sirve de punto de partida para ahondar en los fundamentos conceptuales de la propiedad que, como se intentará mostrar, en su acepción dominante se asientan sobre tal tipo de acumulación para resolver la tensión entre abundancia y escasez que, entre Locke y Hume, ${ }^{4}$ ha servido de base para construir su acostumbrada legitimidad.

Por otra parte, en las últimas décadas se ha dado una creciente incorporación de los bienes y servicios inmateriales a la economía global, la cual ha ido a la par de un movimiento de nuevos cercamientos sobre la naturaleza y la cultura: un proceso de apropiación, similar a los cercamientos ingleses entre los siglos XIV y XVIII, que hicieron crecer las fronteras de la propiedad privada sobre planos hasta entonces caracterizados por formas no directamente privativas de apropiación y de desarrollo productivo. Sin embargo, la creciente hegemonía del trabajo inmaterial ${ }^{5} \mathrm{y}$, más específicamente, de las formas libres y comunes que este puede adquirir, proveen un escenario lo suficientemente atípico como para que tenga sentido discutir sobre nuevas bases aquellos fundamentos tradicionales. En efecto, se verá que la relación entre abundancia y escasez se invierte en un contexto donde es el primero de estos términos el que «ontológicamente» caracteriza lo inmaterial -bienes no rivales y no excluyentes que, en tanto tales, pueden multiplicarse y utilizarse sin detrimento en el uso de los demás- redefiniendo, así, el otrora punto de partida.

Pero para que la mercantilización de lo inmaterial sea posible -no cualquier mercantilización, sino la específicamente capitalista- resulta necesaria una creación artificial de escasez sobre lo que naturalmente se presenta como abundante, interpelándose así el sentido primigenio de la propiedad privada como institución social, esto es, su pretendida «administración libre de lo escaso». De manera que, desde aquí, se propone volver sobre el vínculo entre las concepciones de lo

2 Entendida como la ciencia que analiza el comportamiento humano como la relación entre fines dados y medios escasos de usos alternativos, definición modelada por Lionel Robbins en su Naturaleza y significación de la ciencia económica (1944) que se constituyó como punto de partida de los principales manuales de economía.

3 Es decir, influenciadas por la tradición de la economía clásica de Smith y Ricardo, incluyendo la economía crítica de Marx y remontándose a las primeras definiciones de Aristóteles.

4 Por supuesto, las filosofías de la propiedad se han nutrido del pensamiento de muchos otros grandes filósofos -baste mencionar, por caso, a Kant y a Hegel-. Sin embargo, es posible conceptualizar vivamente la tensión a la que hacemos referencia a través de los argumentos «naturalistas» y «utilitaristas» presentes en Locke y los «pragmáticos» en Hume.

5 En términos generales, el trabajo que produce un bien inmaterial, tal como un servicio, un producto cultural, el conocimiento o la comunicación (Hardt-Negri, 2002: 258). En Imperio, Hardt y Negri distinguen tres grandes formas a partir de su incidencia en el régimen posfordista: primera, aquella que participa de la producción industrial informatizada incorporándose en los procesos de trabajo; segunda, la de las tareas analíticas y simbólicas que se corresponden con la producción de conocimiento y bienes culturales; tercera, la que supone la producción y manipulación de afectos en la interacción y el contacto humanos. En Multitud, sin embargo, van a simplificar la división en dos: por una parte, el trabajo intelectual o lingüístico como puede ser la resolución de problemas, las tareas simbólicas y analíticas o las expresiones lingüísticas; por otra, el trabajo afectivo que produce o manipula afectos (que, a diferencia de las emociones, afectan tanto al cuerpo como a la mente) donde se engloban servicios como el de las asesorías jurídicas, el de las azafatas de vuelo, el de las cadenas de comidas rápidas, etc. (Hardt-Negri, 2004: 136). 
económico y las definiciones de la propiedad, con el objetivo de introducir algunos elementos que permitan una crítica para lo que entendemos como una construcción histórico-social que se muestra cada vez más reactiva frente a las nuevas relaciones productivas del trabajo inmaterial, en primera instancia, y sobre las del trabajo en general, en última.

\section{Los fundamentos de la propiedad privada}

A través de una conocida distinción de ascendencia aristotélica, ${ }^{6}$ Karl Polanyi (1996) va a reconocer dos significados para el término económico: uno sustantivo, que emerge de la dependencia de la subsistencia humana a su entorno, y otro formal que surge del carácter lógico de la relación medios-fines (p. 91). ${ }^{7}$ Más específicamente, define a la «economía sustantiva» como el "proceso instituido de interacción entre el hombre y su ambiente, que tiene como consecuencia el continuo abastecimiento de los medios materiales para la satisfacción de las necesidades" (p. 160). Por otra parte, la «economía formal» refiere al mecanismo lógico que supone la maximización de la relación medios-fines, por lo cual "implica un conjunto de reglas relativas a la elección entre los usos alternativos de los medios insuficientes" (p. 160).

Esta definición formal (o analítica) remite en su acepción actual a la fórmula descripta por Lionel Robbins a mediados del siglo XX, cuando definió a la economía como "la ciencia que estudia el comportamiento humano en cuanto relación entre fines y medios escasos que tienen usos alternativos" (1944, p. 39). De acuerdo con su argumentación, desde una perspectiva económica la existencia humana contendría cuatro características fundamentales: una variedad de fines (primera) de diversa importancia (segunda), con medios limitados para alcanzarlos (tercera) y susceptibles de una aplicación optativa (cuarta). Por sí misma ninguna de estas características contiene un aspecto económico, el cual sólo aparecerá en la combinación simultánea de las cuatro. Es decir:

cuando el tiempo y los medios de lograr determinados fines son limitados y capaces de aplicarse optativamente y cuando los fines son susceptibles de distinguirse entre sí en un orden jerárquico de importancia (Robbins, 1944, p. 36).

Así, la economía se va a concebir como la ciencia de la elección bajo condiciones de escasez y va a ser orientada por la racionalidad instrumental, esto es, por la maximización de la relación entre los medios y los fines.

Robbins define lo económico en torno a un aspecto particular de la conducta: el impuesto por la influencia de la escasez. Sigue el camino trazado por Walras cuando

6 Nos referimos a la distinción que realiza Aristóteles en el Libro I de la Política entre una crematística natural vinculada a la economía, que es el medio para el acrecentamiento de la riqueza para una economía cuyo fin son las condiciones materiales para la vida plena, y una crematística no natural, donde el medio se transforma en fin al buscar el acrecentamiento de la riqueza por la riqueza misma. No debería pasar desapercibida la relación que se establece entre la economía y las vidas política y filosófica -la primera es condición de posibilidad de las segundas- y de la crematística no natural con la vida voluptuosa -la primera es expresión de la segunda-.

7 Vale aclarar que para Polanyi la distinción se basa en una diferencia ontológica ya que "en un caso [el de la definición formal] se trata de las leyes del entendimiento; en el otro [el de la definición sustantiva], de las leyes de la naturaleza" (Polanyi, 1976, p. 155). 
identificó la riqueza social como el "conjunto de cosas materiales o inmateriales que, por una parte, nos son útiles y que, por otra, no están a nuestra disposición más que en una cantidad limitada". ${ }^{8}$ Pero al plantear la propia definición en función de la conducta humana, realiza un movimiento de abstracción que le permite construir una noción todavía más general de lo económico donde la riqueza deviene un concepto relativo al no definirse por cualidades sustanciales sino por su carácter escaso. Desde esta noción de escasez, la utilidad como categoría enteramente subjetiva aparecerá teniendo su expresión objetiva en la demanda.

El ejemplo elegido para ilustrar el carácter relativo de la riqueza es un hecho económico que debió enfrentar Winston Churchill al finalizar la Segunda Guerra Mundial, cuando la alta producción de armamentos vigente hasta entonces dejó de tener sentido en el momento en que se firmó el armisticio: "lo que a las 10.55 de esa mañana era riqueza y capacidad productiva, a las 11 había dejado de serlo, convirtiéndose en una des-riqueza, en un estorbo y en una fuente de desperdicio social" (Robbins, 1944, p. 77). Ciertamente, la sustancia de lo producido no había cambiado, las armas eran las mismas, y sin embargo su valor cayó drásticamente por la modificación en las circunstancias sociales. Robbins concluye que la escasez de los medios era diferente porque los fines habían cambiado.

Por supuesto, que la demanda sea condición necesaria del intercambio mercantil es un hecho que no necesita ser discutido. Pero el ejemplo elegido ilustra claramente una asociación de importancia, aquella que va de una utilidad subjetiva a una demanda objetiva. En efecto, la pretensión de objetividad que las posturas neoclásicas montan sobre la demanda tiene como base una concepción enteramente subjetiva de la utilidad: en la línea walrasiana, esta última será resultado de "relacionar las disponibilidades con la noción movediza de necesidad (o deseo) que se tenga de ellas" (Naredo, 1996, p. 234). Y justamente para que la utilidad como categoría enteramente subjetiva pueda tener una expresión objetiva en la demanda, es necesaria una mediación que sólo será posible con la adaptación de lo escaso "a la medida de lo valorable e intercambiable" (Naredo, 1996, p. 232). Sólo entonces la escasez puede aparecer como un concepto a la vez subjetivo y relativo, y en tanto tal constituirse como la mediación que le permitirá a la economía neoclásica plantearse como una ciencia con pretensiones tanto de objetividad como de neutralidad valorativa.

A este respecto es especialmente interesante la nota aclaratoria del mismo Robbins sobre el uso del término riqueza. Después de definirlo como equivalente al flujo de bienes económicos, agrega que el mismo no es lo suficientemente sólido, y recomienda que no sea utilizado en una definición rígida de lo económico. La razón esgrimida es que "sería bien paradójico tener que sostener que la riqueza disminuiría si los bienes económicos, gracias a su multiplicación, llegaran a convertirse en bienes gratuitos" (Robbins, 1944, p. 75). ${ }^{9}$ La definición analítica de lo económico por principio es lo suficientemente amplia como para abarcar toda conducta humana con arreglo a fines a partir de medios escasos, y sin embargo dejaría de tener sentido en un mundo donde todos los bienes fueran gratuitos... Un mundo, pues, en el que ningún consumo (fin) o costo (medio) merecería la denominación de «económico».

En esta aparente contradicción se manifiesta prístinamente el supuesto que da

8 L. Walras, Eléments d'économie politique pure, p. 2, citado por J. M. Naredo, La economía en evolución. Historia y perspectivas de las categorías básicas del pensamiento económico, p. 202

9 Se volverá sobre la paradoja, dándole un nuevo contexto, sobre el final del presente texto. 
sentido a la definición formal. Robbins, cuando asocia lo gratuito a lo abundante y el precio a lo escaso, indica cuál es su punto de partida: la economía mercantil, en el sentido que Polanyi da al término. No alcanza simplemente con una serie de relaciones entre medios y fines en un contexto de escasez para constituir el objeto de la economía, justamente porque el significado de escasez-del cual depende la definición formal- sólo tiene sentido dentro de la referencia de un determinado mecanismo de oferta-demanda-precio (específicamente de aquel que surge con la mercantilización de la tierra y del trabajo entre los siglos XVI y XIX). Por esto mismo, quizás la definición más sincera para los neoclásicos sea aquella que entiende a la economía como "el estudio de la disposición de mercancías escasas" (Robbins, 1944, p. 64), donde cabe subrayar a la «mercancía» como una noción ontológicamente previa a la de «escasez». Es la mercancía la que da lugar a la escasez, y no a la inversa.

Ahora bien, la escasez como concepto económico tiene un origen material. Para las justificaciones modernas de la propiedad privada, el punto de partida fue la limitación que suponía una escasez que de hecho afectaba a las relaciones de los hombres con las cosas. Para Hume, por ejemplo, "la situación de los objetos consiste en su facilidad de cambio, unida a su escasez en comparación con las necesidades y los deseos de los hombres" (Hume, 1992, p. 664). De esta combinación entre un interés ilimitado de acumulación y una escasez física de lo acumulable se seguía la necesidad de dividir la posesión de los bienes instaurando la propiedad privada.

La excepción, por supuesto, es la argumentación iusnaturalista de Locke que, con la asociación entre cuerpo, vida y propiedad, pone en el trabajo humano la fundamentación más básica para el derecho de apropiación. Su punto de partida es una abundancia garantizada por los límites de la naturaleza que hacen depender la propiedad privada "del trabajo humano y de lo que resulte conveniente para la vida" (Locke, 2002, p. 30). Se trata de una etapa de la historia de la humanidad que Locke caracteriza como "pobre y virtuosa", similar a la organización económica de las sociedades primitivas, en la que los recursos comunes proliferan debido a una asociación de hecho entre lo apropiable y lo utilizable cuyo tope está dado por la finitud de las necesidades materiales. En este primer momento en el que cada hombre sólo puede apropiarse legítimamente de aquello que puede trabajar y usar, las dos leyes de la razón natural que sostienen el esquema lockeano -que las cosas no se echen a perder y que queden en igual cantidad y calidad para el uso de los demásquedan satisfechas sin mayor inconveniente.

Sin embargo, con la institución social del dinero el derecho de apropiación deja de estar atado a lo consumible y pasa a depender sólo del trabajo. La primera ley queda superada gracias a la existencia del oro que, siendo una cosa a la vez perdurable y escasa, pudo constituirse como medio de cambio y acumulación, superando a su vez a la segunda ley con el pacto que instauró el uso de la moneda. ${ }^{10}$ Así, se rompe la frontera fáctica que imponía el carácter finito de las necesidades humanas y, con la posibilidad de acumulación, se libera a la apropiación de toda restricción. En este contexto la regla de la propiedad por la cual cada hombre debería tener tanto como es capaz de utilizar invierte su sentido, y lo que antes era una restricción aparece ahora como estímulo.

10 Tanto en Aristóteles como en Locke, el consenso es la base para el uso de la moneda. El carácter social del pacto, sin embargo, es particularmente relevante en el caso del segundo, ya que implica acordar la legitimidad de la acumulación individual ilimitada. 
Cuando la producción deja de estar atada al consumo y pasa a asociarse a la acumulación, la motivación económica general comienza a regularse fundamentalmente por el ansia de riqueza. Se crea entonces un desfase entre ese deseo ilimitado y los límites propios del mundo físico, y lo que en principio era visto como abundante $-\mathrm{y}$ de hecho lo era- se convierte en escaso. Es justamente en este punto cuando las posturas de Locke y Hume se emparentan:

la misma regla de propiedad, a saber, que todo hombre debería tener tanto como lo que es capaz de utilizar, puede seguir aplicándose en el mundo ${ }^{11}$, sin perjuicio de nadie, dado que hay tierras suficientes en el orbe para abastecer al doble de habitantes, si la invención del dinero, y el tácito acuerdo de los hombres a atribuirle valor a la tierra, no hubiese dado lugar ${ }^{12}$ a apoderarse de extensiones más grandes de tierra y a tener derecho a ellas (Locke, 2002, p. 31).

Y si bien en el caso de Locke la propiedad privada es causa, y no consecuencia, de la escasez de las cosas, en ambos planteamientos el trasfondo crematístico de lo económico originado por el ideal de acumulación ilimitada crea esa determinación particular de la relación entre propiedad privada y escasez por la cual ambas se terminan implicando mutuamente. En este sentido, podría cimentarse la idea de que no es la propiedad la que se fundamenta sobre la escasez, sino a la inversa: la escasez surge con la invención de la propiedad privada, en tanto la mercancía es condición de posibilidad de la acumulación, siendo finalmente esta última la que definirá el carácter de lo escaso. ${ }^{13}$

\section{Los nuevos cercamientos sobre el trabajo inmaterial}

La noción de trabajo inmaterial adquiere especial importancia en el marco de los profundos cambios económicos, políticos y sociales experimentados desde los años '70 a partir de la crisis del modelo productivo sobre el cual el capitalismo se desarrolló a lo largo del siglo XX. Es sabido que a fines de esa década el taylorismo -organización científica del trabajo- y el fordismo -organización científica del trabajo más la mecanización $-{ }^{14}$ encontraron serios límites para garantizar el aumento

11 A nuestro criterio, en este caso correspondería una traducción literal del original en inglés: "would hold still in the world", es decir, "podría seguir aplicándose en el mundo".

12 En el texto original en inglés, Locke agrega aquí entre paréntesis: "by consent”, es decir, "por consenso", lo que denota el carácter social de la acumulación.

13 Esta brevísima exposición de la relación entre propiedad y escasez en Locke y Hume podría entenderse como expresión del individualismo posesivo de MacPherson (1998), pero de ninguna manera busca tomar posición en el debate exegético. Responde, antes bien, a cómo las teorías clásicas de la propiedad son retomadas en el éthos contemporáneo, y particularmente en los debates sobre propiedad intelectual. Como afirmara Polock -sin detrimento de su oposición a la interpretación macphersoniana-, la visión moderna de la propiedad suele relacionarse con el advenimiento del capitalismo y, más puntualmente, con dos cambios culturales de envergadura: la adquisición ilimitada liberada de las restricciones morales y la creciente preponderancia de las relaciones económicas por sobre el resto de las relaciones sociales (Polock, 2002: p. 105). Es, precisamente, este sentido común el que se tiene aquí en mente, en tanto se espera discutir con las nociones que le sirven de apoyo.

14 Básicamente, el taylorismo hace referencia a la división de tareas en el proceso de producción y el fordismo a la producción en serie. Sin embargo, el fordismo puede verse como la maduración del taylorismo y la implementación efectiva de muchas de sus ideas teóricas y, por ende, entenderse como "la forma por la cual la industria y el proceso de trabajo se consolidaron a lo largo del siglo XX” (Antunes, 2003, p. 21). 
progresivo de la ganancia y mantener en alza las tasas de crecimiento. Más allá de las causas específicamente económicas que llevaron a la crisis (Antunes, 2005: pp. 1520), a principios de la década del ' 80 comenzaron a visualizarse una serie de cambios sistémicos de envergadura: el progresivo abandono del modelo de industrialización, la tercerización de la producción y el desarrollo del sector de servicios, la incorporación de las nuevas tecnologías de la información y la comunicación, la nueva organización de las empresas en forma de red, etc. (Neffa, 2003, p. 172 y ss.). A grandes rasgos, este es el contexto que explica y a la vez fundamenta un consenso general respecto al surgimiento de un nuevo modelo productivo: así, se piensa en el toyotismo como la categoría económica que responde a los cambios mencionados a través de una producción orientada directamente por la demanda y en el posfordismo como nuevo paradigma productivo (Hardt-Negri, 2002, p. 260).

En paralelo a estos cambios, en los últimos años se fue generando un consenso general en las ciencias sociales respecto al lugar privilegiado que adquiriría el conocimiento en la economía contemporánea. Uno de los más enérgicos saltos interpretativos fue el que realizó Manuel Castells con su obra del año 1996, La era de la información, la cual contribuyó fuertemente a asentar la idea de que como respuesta a la crisis se comenzó a vivir una nueva fase estructural del capitalismo. ${ }^{15}$ En efecto, Castells describe las tecnologías de la información y de la comunicación como base fundamental para el proceso de reestructuración socioeconómica de los años ochenta, llegando a proponer la existencia de un nuevo modo de desarrollo informacional donde "la fuente de la productividad estriba en la tecnología de la generación del conocimiento, el procesamiento de la información y la comunicación de símbolos". ${ }^{16}$ Esto lo distinguiría del modo de desarrollo agrario - donde la fuente del aumento del excedente depende del incremento cuantitativo de la mano de obra y de los recursos naturales- tanto como del industrial -donde depende de la introducción de nuevas fuentes de energía. La economía informacional, con el conocimiento como principal fuente de productividad, estaría orientada al desarrollo tecnológico antes que al crecimiento material. Así, se distingue y separa del industrialismo que dominó prácticamente todo el siglo XX: en lugar de una lógica dirigida hacia la maximización de la producción, otra en la que se tiende "hacia la acumulación de conocimiento y hacia grados más elevados de complejidad en el procesamiento de la información" (2001, p. 42).

Al basarse fundamentalmente en el conocimiento, la economía informacional supondrá una conexión especialmente estrecha entre cultura y fuerzas productivas, por lo que habría de esperar "el surgimiento histórico de nuevas formas de interacción, control y cambio sociales" (2001, p. 44). En efecto, aunque para Castells los modos de desarrollo se originan en determinadas esferas dominantes de la sociedad como el proceso de producción o el complejo industrial militar-, la tecnología y las relaciones de producción técnicas se terminan difundiendo en el conjunto de

15 Entre otros, esta idea es compartida por los principales referentes del autonomismo italiano (Hardt y Negri, Virno, Lazzarato), del capitalismo cognitivo (Boutang, Vercellone, Rullani) y de las teorías del fin del trabajo (Gorz, Meda, Rifkin). Por cierto, no puede dejar de mencionarse la importante deuda que existe con las obras pioneras de Coriat El taller y el cronómetro (1979) y El taller y el robot (1990).

16 Castells define los modos de desarrollo como "los dispositivos tecnológicos mediante los cuales el trabajo actúa sobre la materia para generar el producto, determinando en definitiva la cuantía y la calidad del excedente. Cada modo de desarrollo se define por el elemento que es fundamental para fomentar la productividad en el proceso de producción" (Castells, 2001, pp. 42-3). 
las relaciones y estructuras sociales, penetrando y modificando todo el ámbito de la conducta social. En este sentido, los cambios operados en las últimas décadas no refieren simplemente a nuevos modelos productivos -como lo sería el toyotismosino a una nueva forma de funcionamiento del propio capitalismo.

En cualquier caso, la organización científica del trabajo, que en efecto signó la producción económica durante prácticamente todo el siglo $\mathrm{XX}$, es la máxima expresión del modo de funcionamiento del capitalismo industrial. Puede caracterizarse someramente como una racionalización del trabajo marcada por su división social y técnica, que separa las tareas de concepción y de ejecución asignando a los trabajadores individuales solamente estas últimas. Remite básicamente al modelo de la fábrica de alfileres de Smith: tareas simples y repetitivas que, a partir de su fragmentación, generan -a la par de la especialización del trabajador- una mayor productividad. ${ }^{17} \mathrm{El}$ incremento de la productividad resulta entonces de este tipo de intensificación del trabajo (taylorismo) o de la combinación de la organización científica del trabajo con medios de trabajo mecanizados (fordismo). Productividad y rentabilidad se encuentran, pues, asociadas: el aumento de la primera es el medio para el aumento de la segunda.

En efecto, desde Adam Smith en adelante se consideró que la búsqueda de rentabilidad supone, en el capitalismo, el aumento de la productividad y que, por ende, el ansia de riqueza del capitalista en un contexto de competencia resultará en beneficio de la sociedad toda, en tanto que para aumentar sus márgenes de ganancia el capitalista habrá de acrecentar cuantitativamente la riqueza material. No es casual que La riqueza de las naciones comience con el ejemplo de la fábrica de alfileres: la división del trabajo es precisamente aquello que permite tal asociación, como claramente explicita Marx al resaltar los efectos de su desarrollo. De la cooperación a la maquinaria, se traza un camino de productividad ascendente movilizado por la extracción de plusvalía: absoluta, cuando se amplía el trabajo total, y relativa la forma específicamente capitalista- cuando se disminuye, desarrollo tecnológico mediante, el trabajo necesario (Marx, 1968, p. 252 y ss.). En ambos casos, el resultado es una mayor producción de mercancías - es decir, objetos consumibles.

Pero mientras que en el fordismo el capital fijo es claramente el lugar que nutre a la rentabilidad al posibilitar la extracción de plusvalía relativa, con el posfordismo ya no alcanzará con aumentar cuantitativamente la producción sino que la rentabilidad dependerá, en gran medida, de iniciativas de tipo cualitativo (Hardt-Negri, 2011, p. 178). La competencia de precios da lugar a la competencia por la colocación de mercancías, sea a través de la innovación en los propios bienes, sea a través de la creación de nuevas técnicas, organizaciones o mercados. Así, en los últimos años se han multiplicado formas nuevas y variadas de mercancías y servicios inmateriales -baste mencionar a modo ilustrativo que los tres sectores con mayor peso en las exportaciones estadounidenses son la industria del software, la del entretenimiento y las biotecnológicas (entre las que se incluye, por supuesto, la farmacéutica)- ${ }^{18}$ a la par de un movimiento de nuevos cercamientos que ha extendido y profundizado las fronteras de la propiedad intelectual (Boyle, 2003, p. 37 y Moulier-Boutang,

\footnotetext{
17 Tal como afirma Andrea Fumagalli (2010), la representación smithiana de la división técnica del trabajo expresada en el modelo de la fábrica de alfileres- experimentó "una suerte de realización histórica" con el modelo taylorista-fordista de producción (p. 85).

18 Sobre esta cuestión, véase Malina Torrent (2006, p. 165).
} 
2004, p. 107). Al igual que en la Inglaterra de los siglos XV a XVIII se cercaron las tierras comunales, en la actualidad la naturaleza y la cultura aparecen cada vez más como objetos patentables, habilitando la apropiación de investigaciones cada vez más básicas y "por encima de la innovación propiamente dicha, en dominios que hasta entonces eran de competencia de los saberes públicos y de la publicación en las grandes revistas científicas" (Pestre, 2005, p. 96). ${ }^{19}$

Siguiendo a Joan Robinson (1979), este proceso de expansión de las fronteras del capital se explica por el hecho de que para el capitalista el verdadero problema no es producir sino vender (p. 270): ${ }^{20}$ el capitalismo debe responder al desafío de garantizar la realización de la plusvalía, esto es, que exista necesidad de aquello que es producido, lo que en efecto termina logrando con la creación de nuevos bienes y servicios que absorben el poder adquisitivo que ya no va a parar a la industria. Precisamente, la privatización y posterior mercantilización de los bienes inmateriales permite garantizar la realización de las mercancías ${ }^{21}$ tanto por ampliar sobre nuevos territorios la esfera del consumo como por constituir un nuevo escenario para la canalización de esos deseos consumistas. En efecto, una vez objeto de privatización/ mercantilización, ${ }^{22}$ la producción inmaterial no representa ningún límite respecto al objeto y al carácter de lo consumible: la única restricción de los nuevos modelos de negocios es su funcionalidad, al tiempo que los bienes inmateriales en sí mismos sólo se encuentran limitados por la imaginación humana. En este sentido, los nuevos cercamientos serían una novedosa respuesta a las crisis de sobreproducción del capitalismo, incentivando un consumo continuo, y por tanto fuente de una nueva vitalidad para el modo de producción.

Ahora bien, los productos inmateriales tienen tres características que los distinguen ontológicamente de los propiamente materiales: por una parte, son no excluyentes y no rivales, es decir, pueden ser utilizados por cualquier individuo sin restringir, cualitativa o cuantitativamente, el uso de los demás; por otra parte, su costo de reproducción tiende a cero, de manera que, una vez producidos, resulta cada

19 Al respecto, dos hechos puntuales pueden mencionarse como hitos en la expansión de la privatización contemporánea: el patentamiento del primer organismo modificado en 1981, que impone un cambio de criterio a partir del cual prácticamente cualquier invención humana puede ser objeto patentable (Rifkin, 2009, p. 132), y la constitución del Acuerdo sobre los Aspectos de los Derechos de Propiedad Intelectual relacionados con el Comercio (ADPIC) de la Organización Mundial de Comercio (OMC) en 1994, que instaura un nuevo régimen en derechos de propiedad intelectual a nivel mundial (Drahos, 2009, p. 53 y ss.). En ambos casos, Estados Unidos tuvo un papel protagónico: fue el agente que impulsó activamente los cambios y logró imponerlos a nivel global.

20 La afirmación de Robinson se entiende en el contexto de la discusión acerca de los límites en la expansión del capital; en efecto, Robinson retoma la predicción de Rosa Luxemburgo de que el capitalismo se encontrará sin salida cuando ya no pueda expandirse geográficamente, y la profundiza marcando que no es posible solucionar el dilema de la sobreproducción -resultado de una productividad siempre creciente- con un aumento parejo del poder adquisitvo - propuesta de raigambre keynesiana- ya que eventualmente se dejará de encontrar demanda para los productos físicos que se prestan a la producción en serie -es decir, para las mercancías materiales estandarizadas-.

21 No es casual que su profusión vaya acompañada de distintas estrategias «antiproductivas», como la obsolescencia programada, las estrategias de ventas o el control de los canales de distribución. Sobre esta cuestión y la evolución del concepto de antiproducción, véase Baran y Sweezy (1976: 272), Deleuze y Guattari (1995: 245) y Lazzarato (2013: 178).

22 Si bien de acuerdo al contexto ambos términos podrían considerarse equivalentes, corresponde distinguirlos. La privatización es condición para determinado tipo de mercantilización, por ejemplo, aquella basada en la propiedad privada; sin embargo, podría existir mercantilización bajo otros tipos de propiedad -como ocurre, por ejemplo, con el software libre, que, aunque libre, puede distribuirse por un cánon. 
vez más barato multiplicarlos; por último, al construirse fundamentalmente en base al conocimiento, tienen un carácter intrínsecamente común, ya que cada uno de ellos depende directamente del cúmulo de ideas producido por la humanidad. El trabajo inmaterial se constituye entonces sobre la base de una economía de la abundancia, donde no existen en principio restricciones de uso, sea en términos de consumo o de producción. ${ }^{23} \mathrm{El}$ modelo productivo es el que históricamente ha caracterizado a la ciencia, ${ }^{24}$ al menos en relación a la apropiación común de los descubrimientos y a su difusión abierta entre pares, esquema el cual se ha reflejado directamente en formas libres de propiedad, como el copyleft. ${ }^{25}$

De manera que, en razón de estos caracteres, para que la mercantilización pueda darse de forma capitalista - es decir, que pueda garantizar la maximización de la rentabilidad-, esta debe sostenerse sobre la privatización. Los bienes inmateriales sólo pueden ser medios para la maximización de la rentabilidad en tanto se constituyan como mercancías diferenciadas. Y para esto es necesario crear una serie de mecanismos extraeconómicos -fundamentalmente de carácter legal, pero no solamente- que moldeen los bienes inmateriales a la forma de lo excluible. En otras palabras, introducir el carácter de lo escaso en ellos, lo cual es garantizado fantásticamente por las nuevas formas de la propiedad intelectual.

La privatización excluyente de aquello que es común y tiene un carácter abierto y libre se explica, obviamente, por la necesidad de volver «productivo» al trabajo inmaterial. El trabajo productivo en el capitalismo es aquel que produce plusvalía (Marx, 2001, p. 77), de manera que ante bienes útiles aunque abundantes como lo son los inmateriales, no queda otra opción más que imponerles artificialmente la escasez: es el único medio para poder generar una mercantilización que permita una maximización de la rentabilidad y funcionar así como medio para la acumulación ilimitada. Lo que debe tenerse en cuenta, sin embargo, es que -con este movimiento sobre el trabajo inmaterial- el capitalismo pierde buena parte de la legitimidad que pudiera haber tenido la mentada asociación entre rentabilidad y productividad de su forma industrial. La ligazón causal entre ansia de riqueza y eficiencia productiva deja de tener sentido, porque en este caso el capitalismo debe limitar la multiplicación de los bienes para poder utilizarlos como mercancías que permitan no sólo una ganancia sino, antes bien, la maximización de esta. En la producción inmaterial, la relación rentabilidad-productividad como eje organizador de la acumulación da así lugar a su opuesto: una relación entre rentabilidad y exclusión.

23 Un bien económico material es rival y excluyente: el tamaño de una fábrica, por ejemplo, limita la cantidad de obreros que pueden trabajar simultáneamente en ella. Un bien económico inmaterial, por el contrario, no encuentra ninguna limitación intrínseca, más allá del medio material que le sirve de soporte: así, por ejemplo, la tecnología CRISPR/Cas 9 de edición genómica podría utilizarse simultáneamente por un número ilimitado de científicos.

24 Al menos en una visión como la de Robert K. Merton, quien identifica cuatro imperativos institucionales que definirían al éthos de la ciencia moderna: universalismo, comunismo, desinterés y escepticismo organizado. El segundo elemento, que se entiende en el sentido extendido de "propiedad común de los bienes", refiere a la idea de que los resultados de la investigación científica son producto de la colaboración social y que, por ende, deben ser asignados al conjunto de la comunidad (Merton, 1973: 273).

25 El copyleft es el mecanismo legal, nacido en el interior del movimiento de software libre, que permite la creación de obras libres, es decir, obras que todos pueden utilizar, modificar, distribuir y crear a partir de ellas obras derivadas. Debido a su cláusula absorbente, la cual indica que toda derivación de una obra copyleft debe mantener la misma licencia, impide la apropiación privativa de las obras libres. Cfr. Stallman (2004, p. 96). 


\section{La construcción económica de la escasez}

Si la lógica del capital puede imponerse sobre la producción inmaterial, si puede darse una homologación de la propiedad de los bienes intelectuales a la propiedad privada de los bienes materiales, debería pensarse que el movimiento inverso también es posible: trasladar la lógica de la propiedad libre -válida y hasta natural para la producción inmaterial- a los bienes materiales. Por supuesto, hay una diferencia importante entre uno y otro tipo de bienes: mientras los inmateriales están caracterizados por la abundancia, los materiales lo están por la escasez. Sin embargo, la escasez no tiene que ser pensada en términos absolutos sino relativos: incluso para la economía formal los bienes económicos son escasos en relación a las necesidades y los deseos de los hombres, que se presentan como ilimitados.

De acuerdo con Robbins, la economía no tendría sentido en un mundo donde todos los bienes fueran abundantes, lo que es una afirmación natural para la definición analítica de lo económico, ya que esta depende de la cosmovisión capitalista. Su noción de riqueza supone la propiedad privada, en un sentido particular de ella, es decir, como medio para la acumulación. Ella funciona como la mediación necesaria para construir la asociación entre valor y escasez de la que depende la especificidad de lo económico, ya que-dentro del capitalismo- los fines económicos se constituyen a partir del ansia ilimitada de riqueza, siendo en función de este carácter ilimitado de los fines como se establece la condición de escasez de los medios.

Es por esto por lo que si el aire no es considerado un bien económico por la economía formal no es tanto por su abundancia natural sino porque hasta el momento no se encontró un método para excluir a las personas de su uso común. Exactamente lo contrario ocurrió con la tierra, cuya renta sólo es posible por su cercamiento y posterior mercantilización, los dos hechos históricos que determinaron su actual carácter escaso (Polanyi, 2007, p. 81 y ss.). Y lo mismo debería aplicarse a los bienes económicos en general, al menos en tanto sea posible pensar formas de organización alternativas a las de la propiedad privada. En otras palabras, la escasez aparentemente objetiva de los medios económicos está dada originaria y fundamentalmente por la privatización general de los bienes. ${ }^{26} \mathrm{La}$ explicación del valor y el sentido de la propiedad privada dependen precisamente del desacoplamiento entre los deseos ilimitados de acumulación y la finitud del mundo físico. Al pensar lo económico en función de la conducta, la economía formal va a trasladar este desfase a la relación medios-fin. Con este movimiento de abstracción lo económico se termina de separar de lo físico, profundizando la ruptura epistemológica postfisiocrática a través de la universalización de una visión particular del mundo: la equivalencia entre racionalidad económica y racionalidad instrumental es, en efecto, la victoria de la crematística como paradigma de la práctica económica. Pero de ninguna manera puede proclamarse el derecho -como la pretensión de neutralidad y de objetividad dan a entender- de ser el único paradigma posible. Su fortaleza proviene del respaldo que le da una organización económica constituida durante los últimos cinco siglos de la historia de la humanidad en base a la propiedad privada de los medios de producción.

26 En este sentido, compartimos la afirmación de que "lo que marca la apoteosis de la modernidad y de la sociedad de mercado (del capitalismo) es el hecho de que ya nadie puede disponer de medios de existencia distintos de los que provienen directa o indirectamente de la venta de bienes, de servicios o de cualidades en un mercado" (Caillé, 2009, p. 37). 
De acuerdo con Polanyi, los medios se encuentran intrínsecamente limitados por los fines, y por lo tanto son estos últimos los que determinarán su suficiencia o insuficiencia. Es por esto que si los fines son ilimitados -como lo son dentro del capitalismo- los medios aparecerán como escasos. Por el contrario, si son limitados -como en la economía aristotélica-, los medios resultarán suficientes o insuficientes en función del contenido concreto de los fines. Es en este sentido en el que Aristóteles rechazó la definición de escasez, ya que "ningún instrumento de arte alguna es ilimitado ni en cantidad ni en magnitud. Y la riqueza es la suma de instrumentos al servicio de una casa y de una ciudad" (Política, 1256b16). En otras palabras, el sustento del hombre no debería suponer -al menos, no ex ante- una situación de escasez.

Si bien esta afirmación no constituye de por sí una refutación del principio capitalista de la escasez, contribuye a socavar la idea de que la escasez es una propiedad necesaria de los bienes económicos al indicar que es en relación a los fines como se establece la escasez de los medios y que, por lo tanto, esta última dependerá de una determinada concepción de aquello que se disponga como objetivo de la actividad económica. Los medios no son naturalmente escasos, es el hombre quien así los concibe; con esto, la justificación pragmático-utilitaria de la propiedad privada pierde su fundamento ontológico. Pero, además, el hombre concibe los medios como escasos al definir, socialmente, el objetivo de la actividad económica; por esto, la afirmación de Polanyi también establece el punto de partida para la crítica a la propiedad, es decir, la discusión sobre el sentido de la actividad vital. ${ }^{27}$

Para la tradición realista -que va de la filosofía griega hasta los economistas clásicos, incluyendo a Marx- la economía se constituye en continuidad con el carácter social de la naturaleza humana. El punto de partida es la idea de que el hombre depende indefectiblemente de su interacción con el ambiente y con los demás hombres para garantizar su sustento. La variedad de necesidades -empezando por la comida y el cobijo como las más básicas-y la imposibilidad de los individuos para autoabastecerse hacen que el hombre dependa de la organización colectiva para garantizar los medios para satisfacerlas. En esta línea, tanto Platón como Aristóteles explicarán a partir de aquí el origen de la pólis, que compartirá con la economía un mismo fin: la autosuficiencia. ${ }^{28}$ Esta será justamente la base sobre la cual los economistas clásicos constituyen su concepción de la riqueza, que es asociada al bienestar material de la sociedad.

Sin embargo, tal como indica Godelier (1975), a diferencia de estos últimos y para evitar la exclusión de actividades claramente económicas como los servicios o los bienes intelectuales, la tradición realista del siglo XX no retoma la tesis por la cual lo económico es reducido a la riqueza material, sino que define lo económico a partir de un aspecto en particular que puede adquirir una actividad: cuando "conlleva directa o indirectamente el uso de medios materiales" (p. 23). Así, la actividad económica de una sociedad se va a definir como "el conjunto de operaciones por las cuales sus miembros obtienen, se distribuyen y consumen los medios materiales para satisfacer sus necesidades individuales y colectivas" (p. 259). La economía no nace asociada al intercambio mercantil y, en consecuencia, ni la mercancía ni la escasez

27 En este sentido, la refutación del principio capitalista de la escasez requiere una justificación ética y política que excede al presente escrito; sin embargo, creemos que los lineamientos básicos para tal justificación pueden encontrarse en la oposición entre acumulación y tiempo libre que se presenta a continuación.

28 Cfr. Platón, República, 369c y Aristóteles, Política, 1252b8, 1280b34, 1326b4 y Etica Nicomáquea, $1097 \mathrm{~b} 14$. 
son aquí condiciones necesarias para la constitución de su objeto. A diferencia de la perspectiva analítica, entonces, el aire sí podrá ser considerado un bien económico aunque no sea intercambiable: siendo un bien material necesario para la vida, tanto su calidad como su reproducción serán legítimamente problemas económicos cuando impliquen un costo social, al igual que las externalidades negativas que la industria pueda provocar sobre el ambiente.

Por otra parte, la actividad económica de una sociedad va a estar vinculada orgánicamente a las demás actividades políticas, religiosas, culturales que "forman con ella el contenido de la vida de esta sociedad y a las cuales proporciona los medios materiales de realizarse" (p. 259). La economía no se representa como una actividad aislada, ni siquiera autónoma. Queda supeditada a su interrelación con los otros ámbitos de la vida humana, individual y colectiva, que condicionan tanto el contenido de sus objetivos como el modo de alcanzarlos. En este sentido puede decirse que la economía incorpora los límites de aquello que socialmente se considere una vida plena, lo que definiría alternativamente el carácter de lo escaso. Si en la economía formal -es decir, para el capitalismo- es una propiedad intrínseca a todo bien económico debido al carácter ilimitado de la acumulación que da sentido al intercambio, en una concepción material de la economía como la expuesta se definirá en relación a los objetivos sociales de una vida plena, con lo que perdería el carácter absoluto que fenoménicamente los caracteriza.

En el capitalismo el «tiempo libre» es subsumido de una manera particular por el pensamiento económico ortodoxo, que lo adapta en función de un tiempo disponible que es concebidoúnicamente como medio para la acumulación de capital. No es casual, en efecto, que la economía política contemporánea contraste tan ostensiblemente con el legado de la Antigüedad clásica, cuya construcción teórica pasaba ante todo por la calidad y el valor de uso en contraposición a la obsesión por la cantidad y el valor de cambio característica de la Modernidad (Marx, 1968, p. 297). Pero, aun así, su fantasma sigue allí, como se hace claramente patente en la paradoja de Robbins. Que un mundo de bienes sobreabundantes sea un mundo sin riqueza sólo puede mostrar que, en última instancia, la definición de riqueza de la economía formal se encuentra escindida de las condiciones materiales de existencia. Como Marx indicó, el desarrollo de las fuerzas productivas disminuye la riqueza entendida a partir del capital, y esto porque la oposición entre trabajo necesario y tiempo disponible es sustituida en el capitalismo por la oposición entre trabajo necesario y trabajo excedente, haciendo que el tiempo disponible únicamente pueda ser pensado como fuente de rentabilidad. En este sentido, rentabilidad y productividad se encuentran en realidad disociadas, contrariamente al sentido común del pensamiento ortodoxo pero consistentemente con la opinión de Robbins, que puesta en este contexto adquiere casi el carácter de confesión:

El término riqueza se usa aquí como equivalente de un flujo de bienes económicos; pero creo que es claro que existen grandes desventajas en usarlo así. Sería bien paradójico tener que sostener que la riqueza disminuiría si los bienes económicos, gracias a su multiplicación, llegaran a convertirse en bienes «gratuitos». Por eso en cualquier delimitación rígida de la Economía el término riqueza debería evitarse (Robbins, 1944, p. 77).

La alternativa a la resolución del problema de la escasez es, pues, el «tiempo libre»: es decir, concebir los bienes económicos como medios de la vida plena. Es 
en esta línea en la que los teóricos del fin del trabajo -conscientes de la hegemonía capitalista- encontraron en la renta básica universal una propuesta natural ante la efusión de las nuevas formas inmateriales de creación colectiva. Quizás esta posición pueda explicarse porque, hasta los primeros años del siglo XXI, primaba la sensación de que los nuevos cercamientos encontrarían un límite infranqueable en la naturaleza del trabajo inmaterial: su carácter común y libre se veía como una garantía frente a los recurrentes (y hasta entonces fallidos) intentos por privatizarlo. Esta perspectiva pareciera haberlos llevado a creer que, eventualmente, la sociedad se vería obligada a encontrar formas alternativas (y probablemente disruptivas) de financiamiento para el creciente trabajo inmaterial, el cual se multiplicaba con relativa independencia de los medios de remuneración tradicionales. En cualquier caso, y poniendo entre paréntesis el optimismo político, la renta básica universal representa tanto la necesidad como la posibilidad de garantizar las condiciones materiales de existencia para un nuevo tipo de ejercicio de la actividad vital.

En efecto, esta propuesta no responde meramente a la necesidad de encontrar mecanismos de retribución para un trabajo que muestra su creciente utilidad social, sino que es la contracara de una producción que no se concibe como medio para la acumulación sino como un ejercicio del tiempo libre, es decir, como un fin en sí mismo. Y precisamente en este sentido el trabajo inmaterial puede ser, en el marco del capitalismo, disruptivo: es expresión casi natural de una concepción de la producción que, aunque hoy es alternativa, se encuentra en el origen del pensamiento económico y político como aquella que da sentido y racionalidad a la economía como tal, teniendo en la vida plena -entendida como el libre ejercicio de las facultades humanas más propias- su propio fin.

La distinción entre la naturaleza de los bienes inmateriales y los propiamente materiales cumple una función de importancia en tanto que contribuye a romper el sentido común -el éthos capitalista- que asocia el carácter privado de la propiedad a la eficiencia productiva. Permite mostrar cómo otras formas de propiedad son posibles y, para el caso de los bienes inmateriales, aun más racionales en términos de la productividad y la potencia creativa de la humanidad. ${ }^{29}$ Sin embargo, una vez entendido esto la distinción debería matizarse: primero, porque toda forma de propiedad es una construcción social, y, por ende, en el mejor de los casos una adaptación, que puede ser más o menos eficiente pero aun así arbitraria, a determinados elementos naturales -como el carácter aparentemente ${ }^{30}$ escaso de los bienes materiales, o la abundancia de los inmateriales- y en función de determinados objetivos sociales - como la rentabilidad, la productividad, la creatividad, etc. Pero también porque, en el marco de un sistema social que es concebido como un todo, ambas formas de propiedad se afectan mutuamente e inevitablemente habrán de influenciarse.

Esto explica que un sistema de ingreso como el de la renta básica universal pueda aparecer como una medida factible ante la profusión de la producción inmaterial,

29 Además del movimiento de software libre, que mostró la potencialidad de la creación colaborativa al producir un sistema operativo de primera línea como GNU/Linux, quizás el más patente ejemplo de la potencia creativa no crematística sea la ciencia moderna, constituida como actividad común y abierta entre pares.

30 «Aparentemente» porque, si bien existen diferencias objetivas entre los bienes materiales e inmateriales en relación a su carácter escaso o abundante, a lo largo del texto se ha impulsado la idea de que su forma se constituye socialmente siendo, en el marco del capitalismo, la lógica de la acumulación la que define la idea de escasez que prima sobre lo material (y cada vez más sobre lo inmaterial). 
aun en el contexto capitalista. De igual manera, los distintos límites que se discuten sobre la propiedad intelectual tendrían, o podrían tener, su contrapartida en la propiedad material: no es fundamentalmente distinto limitar el monopolio de las ideas a través de duraciones más breves que limitar el monopolio empresario a través de leyes anti-trust, anti-cartel o, incluso un paso más allá, de limitación de la herencia. En esta línea, si, por ejemplo, se pensara que es lícita la instauración de formas privativas, más o menos limitadas, sobre la propiedad intelectual -como suelen creer tanto defensores como detractores-, ${ }^{31}$ igualmente lo sería la creación de distintos mecanismos de limitación de la acumulación basada en la propiedad privada material.

Sin embargo, como ya se ha dicho, en la actualidad la influencia pareciera ser de las formas privativas de la propiedad material, que avanzan cada vez más sobre las formas libres de la inmaterial. Lo que resulta perfectamente consistente con el hecho de que en los debates sobre propiedad intelectual poco y nada se discute sobre la propiedad en general, o la propiedad material en particular. Las posturas críticas sobre la propiedad intelectual -de raigambre liberal o no- mantienen demasiado a rajatabla la separación entre la naturaleza de uno y otro tipo de bien, concibiendo a esa separación como principal fuente de legitimidad para el objetivo de mantener formas libres o abiertas para la propiedad intelectual. Desconocen, pues, la discusión de fondo, dejando la puerta abierta a una propertización creciente -que así también puede nutrirse de la idea de que ambas formas de propiedad, privativa y abierta, podrían convivir en la producción inmaterial- y evitando avanzar sobre lo que sería lícito: las formas generales de la propiedad, que -tanto para los bienes inmateriales como para los materiales- ante todo son expresión de una determinada organización social.

\section{Consideraciones finales: repensar la propiedad, pensar el capitalismo}

De acuerdo con la conocida hipótesis de Karl Polanyi, la institución moderna del mercado como mecanismo de oferta-demanda-precio habría marcado la pauta para la constitución de las acepciones de lo económico dominantes en la actualidad a partir de un fenómeno de articulación del comercio con la vida diaria, y de una consecuente identificación en la práctica entre lo económico y lo mercantil. Esto habría derivado, a su vez, en un error teórico consistente en "igualar la economía humana general con su forma de mercado": la «falacia económica» (Polanyi, 1996, p. 78) de universalizar lo que es sólo una forma posible -coyuntural y producto de una forma histórica particular- de organizar el intercambio. En el contexto posfordista, donde la creciente incidencia del trabajo inmaterial ha llevado a un incesante movimiento de privatización sobre formas productivas que hasta ahora solían tener un carácter común, esta tesis adquiere una renovada actualidad.

31 A este respecto, cabe mencionar el conocido debate entre Richard Epstein y Richard Mossof, donde si bien se colocan en veredas opuestas - la postura de Mossof es naturalista y defensora de la propiedad intelectual como equivalente a la propiedad privada material, mientras la de Epstein es utilitarista y crítica de una homologación fuerte entre ambos tipos de propiedad- terminan encontrándose en un punto intermedio al considerar que la regulación de la propiedad intelectual debe imponerle ciertos límites como el temporal para evitar monopolios, o un margen amplio para el uso justo para garantizar la circulación del conocimiento y la cultura. Sobre esta cuestión, véase Epstein (2004) y Mossof (2005). 
En este sentido, la relación entre el trabajo inmaterial y la propiedad habilita a un doble movimiento: por una parte, clarificar la presencia de una serie de caracteres -su carácter común y libre, fundamentalmente- que tendrían la capacidad de constituir la base para una organización productiva potente, alternativa y posiblemente disruptiva en relación al «individualismo posesivo» del mercado moderno; por otra, repensar la propiedad, en general, no sólo para clarificar su carácter histórico-social sino, más importante, los principios y objetivos que le dan sentido en el marco del modo de producción actual. Parece claro que frente a los nuevos cercamientos sobre la naturaleza y la cultura se vuelve una tarea urgente pensar hasta dónde sería deseable o lícito extender la lógica de la propiedad privada. Pero, partiendo de su intenso avance y dado que acumulación y escasez parecieran establecer una relación de mutua dependencia entre sí, igualmente importante sería avanzar hacia una crítica de la propiedad en general.

Tareas como estas deberían llevar, por último, a una discusión aún más amplia sobre el sentido de la producción humana. Si acumulación y escasez se encuentran efectivamente asociadas, y si la construcción artificial de escasez es condición para la acumulación, la crítica a los cercamientos en propiedad intelectual debería extenderse y, eventualmente, traducirse en una crítica a la acumulación como lógica organizativa de las fuerzas productivas de la humanidad. En función de esto, quizás deba retomarse la tradición que, de Aristóteles a Marx, situó en el tiempo libre el fin de la economía, entendido como condición material de la vida plena o, lo que bien podría ser lo mismo, de una producción libre y consciente. Así, cabría entonces la esperanza de hallar nuevos elementos no sólo para la crítica sino también para la invención de alternativas a un régimen institucional que se muestra cada vez más regresivo en relación a las nuevas expresiones de la potencia creativa de la humanidad.

\section{Referencias bibliográficas}

Antunes, R. (2003): ¿Adiós al trabajo?. Bs. As.: Herramienta.

Antunes, R. (2005): Los sentidos del trabajo. Bs. As.: Herramienta.

Aristóteles (2000): Ética Nicomáquea. Madrid: Gredos.

Aristóteles (2000): Política. Madrid: Gredos.

Baran, P. y Sweezy, P. (1976): El capital monopolista. México: Siglo XXI.

Boyle, J. (2003): "The second enclosure movement and the construction of public domain", en 66 Law and Contemporary Problems 33-74. North Carolina: Duke University.

Caillé, A. (2009): "Sobre los conceptos de economía en general y de economía en particular", en Coraggio, J. L., ¿Qué es lo económico?. Bs. As.: Ediciones Ciccus.

Castells, M. (2001): La era de la información, Vol. I: La sociedad red. México: Siglo XXI.

Deleuze, G., y Guattari, F. (1995): El Anti Edipo. Capitalismo y esquizofrenia. Madrid: Paidós.

Drahos, P. (2009): “Derechos globales de propiedad sobre la información: la historia del TRIPS en el GATT", en Mientras Tanto, $N^{\circ} 113$. Madrid, Icaria Editorial.

Epstein, R. (2004): "Liberty versus Property? Cracks in the Foundations of Copyright Law", en John M. Olin Law \& Economics Working Paper $N^{\circ}$ 204. Chicago: University of Chicago Press.

Fumagalli, A. (2010): Bioeconomía y capitalismo cognitivo. Hacia un nuevo paradigma de acumulación. Madrid: Traficantes de Sueños. 
Godelier, M. (1975): Racionalidad e irracionalidad en economía. Bs. As.: Siglo XXI.

Hardt, M. y Negri, A. (2002): Imperio. Bs. As.: Paidós.

Hardt, M. y Negri, A. (2004): Multitud. Bs. As.: Debate.

Hardt, M. y Negri, A. (2011): Commonwealth. El proyecto de una revolución común. Madrid: Akal.

Hume, D. (1992): Tratado de la naturaleza humana. Madrid: Tecnos.

Lazzarato, M. (2013): La fábrica del hombre endeudado. Ensayo sobre la condición neoliberal. Madrid: Amorrortu.

Locke, J. (2002): Segundo ensayo sobre el gobierno civil. Bs. As.: Losada.

MacPherson, C. B. (1998): La teoría politica del individualismo posesivo, Madrid, Trotta

Malina Torrent, T. (2006): "Activismo copyleft", en AA.VV., Copyleft. Manual de uso. Madrid: Traficantes de Sueños.

Marx, K. (1968): El capital. México: FCE.

Marx, K. (2001): El capital, Libro I, Capítulo VI Inédito. México: Siglo XXI.

Merton, R. K. (1973): "The Normative Structure of Science”, en The Sociology of Science: Theoretical and Empirical Investigations. Chicago: University of Chicago Press

Mossof, A. (2005): “Is copyright property?", en San Diego Law Review Vol. 42. San Diego: University of San Diego Press

Moulier-Boutang, Y. (2004): "Riqueza, propiedad, libertad y renta en el capitalismo cognitivo", en AA. VV. (2004), Capitalismo cognitivo, propiedad intelectual y creación colectiva. Madrid: Traficantes de Sueños.

Naredo, J. M. (1996): La economía en evolución. Historia y perspectiva de las categorías básicas del pensamiento económico. Madrid: Siglo XXI.

Neffa, J. (2003): El trabajo humano. Contribuciones al estudio de un valor que permanece. Bs. As.: Lumen.

Pestre, D. (2005): Ciencia, dinero y política. Bs. As.: Nueva Visión.

Platón (2000): República. Madrid: Gredos.

Polanyi, K. (1976): "El sistema económico como proceso institucionalizado", en Godelier, M., Antropología y economía. Barcelona: Anagrama.

Polanyi, K. (1996): El sustento del hombre. Madrid: Grijalbo.

Polanyi, K. (2007): La gran transformación: los orígenes políticos y económicos de nuestro tiempo. Bs. As.: FCE.

Polock, J. G. A. (2002): Virtue, Commerce, and History, Cambridge, Cambridge University Press

Rifkin, J. (2009): El siglo de la biotecnología. Barcelona, Paidós, 2009

Robbins, L. (1944): Naturaleza y significación de la ciencia económica. México: FCE.

Robinson, J. (1979): Contribuciones a la teoría económica moderna. México: Siglo XXI.

Stallman, R. (2004): Software libre para una sociedad libre. Madrid: Traficantes de Sueños. 